\title{
A TEOLOGIA EDUCACIONAL DA REFORMA PROTESTANTE: EDUCAÇÃO EM LUTERO E O CENÁRIO DA MODERNIDADE
}

THE EDUCATIONAL THEOLOGY OF THE PROTESTANT REFORMATION: EDUCATION IN LUTHER AND THE SCENARIO OF MODERNITY Elton Roney da Silva Carvalho ${ }^{77}$

${ }^{77}$ Mestre em Cências dos Religões no PPGCR -UPB Possui graduação en Licenciatura Plena em História pela Universidade Estadual Vale do Acaraú - CE (2009). Curso Live em Teologia pelo Seminário Anglicano Teológico da Paraliba (SAT-PB). Professor de História da Educação Básica na Secretaria de Educação do Estado da Paraiba Professor da Faculdade Internacional Cidade Vwa Emait. etonroneycarvalho@gmail.com 


\section{RESUMO}

A reforma protestante do século XVI gerou uma nova cosmovisão acerca de dimensões fundamentais da sociedade. Sua relevância para a sociedade não diz respeito exclusivamente a dimensão religiosa, mas, interfere nas estruturas políticas, educacionais e econômicas da era moderna. Diante da Modernidade, a reforma propõe alternativas à visão de mundo humanista, iluminista, secular. A teologia educacional da reforma, especialmente nas concepções de Lutero, oferece subsídios para uma formação educacional integral, bíblica e científica, uma vez que está comprometida com a experiência individual do Homem, transforma-o para uma atuação relevante diante do individualismo e do mundo líquido promovido pela Modernidade. Deste modo, utilizando uma abordagem qualitativa e fazendo uso da técnica de revisão bibliográfica, o presente trabalho discute as características da reforma protestante, sua relação com a Modernidade e como as ideias educacionais de Lutero podem oferecer competências para uma atuação cristã diferenciada diante do cenário da Modernidade.

\section{PALAVRAS-CHAVE}

Reforma Protestante. Lutero. Modernidade. Teologia Educacional.

\section{ABSTRACT}

The Protestant Reformation of the sixteenth century spawned a new worldview on the fundamental dimensions of society. Its relevance to society does not exclusively concern the religious dimension, but it interferes in the political, educational, and economic structures of the modern era. In the face of modernity, the reform proposes alternatives to the vision of the humanist, enlightened, secular world. The educational theology of reform, especially in Luther's conceptions, provides a basis for an integral educational, biblical, and scientific education, since it is committed to the individual experience of man, transforms it into an action relevant to individualism and the world promoted by Modernity. Thus, using a qualitative approach and making use of the technique of bibliographical revision, the present work discusses the characteristics of the Protestant Reformation, its relation to Modernity, and how Luther's educational ideas can offer a differentiated Christian performance in the context of Modernity. 


\section{KEYWORDS}

Protestant Reformation. Luther. Modernity. Educational Theology.

\section{INTRODUÇÃO}

A Idade Média é bem definida em padrões sociais, culturais e religiosos. Os limites para os atos sociais do cidadão eram impostos por uma religião dogmática que definia bem o espaço sagrado e o profano. "A Europa Ocidental viveu, no decorrer da Alta Idade Média, uma crise de ansiedade. Até aquele momento, as fronteiras sociais estavam bem delimitadas e a cultura medieval fornecia, de modo geral, um mapa bem ordenado do sagrado e do profano" (GRUMAN, 2005, p. 96).

As reformas religiosas do século XV foram, em sua essência, um movimento religioso que também é possuidor de sua parcela de participação social, uma vez que não se pode afirmar exageradamente esta separação de movimento religioso $x$ movimento social, sendo a religião uma esfera de grande influência na constituição social. Ela tem sua particularidade por ser um movimento religioso que reivindica mudanças religiosas de cunho social. É a crítica eclesiástica ao sistema eclesiástico para resultar em uma mudança social, uma vez que o poder católico romano na idade média tem influência social elevada, sendo esta formadora de um imaginário medieval. A exigência das transformações sociais e eclesiásticas questionam os "dogmas sociais". 78

A Reforma Protestante, fato importantíssimo para este momento, é entendida de duas formas: enquanto alguns estudiosos laicos entendem-na como um caminho natural para a liberdade, defensores papais compreendem-na como uma desestabilização dos princípios de autoridade, de ordem social e disciplina. Formadora de uma nova forma de ver a relação do povo com Deus e com a sociedade, a Reforma "inaugurou" a idade moderna, quando se percebe o povo como participante da história e não apenas subordinados a um poder central, neste caso Sacropolítico. Seu desdobramento político, social e cultural é forte, perpassando pela influência na econômica, como observamos em

\footnotetext{
${ }^{78}$ Por dogmas sociais compreende-se a extensão da influência das leituras sociais da religião na cultura laica. Os dogmas religiosos formam a cultura, perpetuando-se na sociedade; no coletivo e, consequentemente, no indivíduo.
} 
Max Weber e seus trabalhos relacionados a Ética Protestante e a sua ligação ao Espírito do Capitalismo.

As fronteiras e as relações entre a religião e o espaço público ganham novas facetas e possibilidades na passagem da modernidade para a pós-modernidade. Evidente que o debate modernidade/pós-modernidade é carregado de ensaios e críticas $^{79}$. A modernidade impõe desafios específicos ao Homem e, dentre eles, a própria crítica de si mesmo. Inserido nesta crítica temos as afirmações de verdades universais nas diversas religiões, principalmente na Europa, com o cristianismo Católico Romano. É notório que nosso modo de viver atual é reflexo de uma situação histórica europeia iluminista. A crítica Racionalista e o Renascimento são formadores da modernidade e da substituição de afirmações religiosas por elaborações racionais.

Nossa época se desenvolveu sob o impacto da ciência, da tecnologia e do pensamento racional, que tiveram origem na Europa dos séculos XVII e XVIII. A cultura industrial ocidental foi moldada pelo iluminismo - pelos escritos de pensadores que se opunham à influência da religião e do dogma e desejavamsubstituí-los por uma abordagem mais racional à vida prática (GIDDENS, 2000, p. 13).

A religião no espaço público traz suas consequências sociais em nossa contemporaneidade de forma acentuada. O controle da religião neste espaço não é tema recente. Desde o surgimento da crítica à hegemonia católico-romana na Europa que percebe-se a presença da religião nos debates significativos nas diversas esferas sociais. Segundo Marilena Chauí, é uma passagem do público para o privado que caracteriza este momento histórico.

\footnotetext{
79 "Tanto a contemporaneidade deve seu modo de ser a modernidade que o debate se dá a respeito de uma pergunta: a modernidade acabou ou se instaurou uma nova fase interna a ela mesma que poder nem ser a última?". CAMPOS, Breno Martins. Fundamentalismo Protestante: a invenção de uma tradição exclusivista na modernidade. PUC-SP; UPM). Disponivel $<$ http://uww.dhi.uem.br/gtreligiao/pdf/st3/Campos,\%20Breno\%20Martins.pdf> Acesso em 09 fev. 2018.
} 
De um lado, procurou controlar a religião, deslocando-a do espaço público (que ela ocupara durante toda a Idade Média) para o privado. Nesta tarefa, foi amplamente auxiliada pela Reforma Protestante, que combatera a exterioridade e o automatismo dos ritos assim como a presença de mediadores eclesiásticos entre o fiel e Deus, e deslocara a religiosidade para o interior da consciência individual. De outro, porém, tratou a religião como arcaísmo que seria vencido pela marcha da razão ou da ciência, desconsiderando, assim, as necessidades a que ela responde e os simbolismos que ela envolve. Julgou-se que a modernidade era feita de sociedades cuja ordem e coesão dispensavam o sagrado e a religião, e atribuiu-se à ideologia a tarefa de cimentar o social e o político. (CHAUI, 2004, p. 153).

A religião ganhou espaço no subjetivismo individual. Entretanto, o estado laico se forma, gerando a secularização e o abandono da relevância social da religião frente às descobertas científicas, ou, uma "fé na ciência". O domínio público do religioso se fechou, mas, a individualidade e a pessoalidade da religião ganha espaço. Constrói-se uma ideia de um Deus relacional e uma interpretação baseada não apenas na Doutrina, na Tradição ou no conhecimento teológico, mas, essencialmente na experiência (esses, pilares de uma escolástica moderna, baseada na Filosofia para aprimoramento da Teologia como resposta a Modernidade).

\section{NOVAS FRONTEIRAS ENTRE A FÉ CRISTÃ, A MODERNIDADE E O INDIVÍDUO}

A modernidade trouxe, como dito, desafios ao Homem moderno. Ele se vê, inevitavelmente, sem um suporte ontológico. Abrir mão de sua individualidade em detrimento de uma coletividade se torna algo incompreensível. Como a modernidade cria um padrão de comportamento quase que generalizado, o indivíduo ganha espaço, pois, na medida em que se vê fruto de 
uma realidade dada e racional também se enxerga como indivíduo capaz de afirmar suas convicções pessoais, subjetivas e, também, religiosas. "Essas determinações provocam mudanças no sujeito, pois, a imposição de padrões de vida traz consequências de exclusão para o indivíduo, que não consegue ser aquilo que é, mas, sim o que a modernidade o impõe" (MELCHIOR, 2009, p. 1). A "modernidade líquida" permite as possíveis, necessárias e constantes mudanças na constituição da sociedade moderna. A reformulação da sociedade e de seus paradigmas é uma consequência dela. Os padrões sociais não estão definidos nem impostos, pois, as características individuais são presentes. Nesta modernidade existem características específicas que podem ser definidas na Pluralidade, Secularização e na Racionalidade.

Acerca da subjetividade, Bauman afirma:

Esse sentimento só pode vir de um sentimento do tempo, do tempo preenchido com seus cuidados - sendo estes o fio precioso com que se tecem as telas resplandecentes da ligação e do convívio. A receita ideal de Friedrich Nietzsche para uma vida feliz, plenamente humana - um ideal que ganha popularidade em nosso tempos pós-modernos ou 'líquidos modernos', é a imagem do Super homem, o grande mestre da arte da autoafirmação, capaz de evadir ou escapar de todos os grilhões que restringem a maioria dos mortais comuns. OSuper homem é um verdadeiro aristocrata - 'os poderosos, os bem situados, os altivos, que pensavam que eles mesmos eram bons, e que suas ações eram boas' quer dizer, até se renderam à reação e à chantagem da ressentimento vingativo de 'todos os vis, os pobres de espírito, os vulgares os plebeus', recuaram e perderam sua autoconfiança e determinação. (BAUMAN, 2008, p. 28)

A racionalização científica trouxe, também, o "desencantamento do mundo", tendo ampla contribuição na reforma protestante. Esse "desencantamento" pode ser entendido não apenas como a negação da religião e de seu papel, mas, em relação ao Homem e sua forma de ver o mundo. O avanço das 
pretensões científicas possibilita, como dito acima, uma fé na ciência, que, posteriormente, permite um retorno ao fenômeno religioso e sua atuação no mundo. O significado dado ao sentido "desencantamento do mundo" é capaz de nos fazer compreender o que ocorre no fenômeno moderno/pós-moderno.

Descubro no meio dessa travessia, e demonstro, que os dois significados encontrados são concomitantes na biografia de Weber. Eles se acompanham um ao outro sabendo-se entretanto distintos, na medida em que dizem ora o desencantamento do mundo pela religião (sentido ' $a$ '), ora o desencantamento do mundo pela ciência “(sentido 'b') (PIERUCCI, 2003, p. 42)

O processo de Secularização é extremamente formador de um caráter cultural atual. Ele não apenas forma como é o próprio resultado da negativa da religião no espaço público, mas, não apenas desta, também da crítica avassaladora da metafísica e dos valores universais, das afirmativas dogmáticas sobre "verdade" ontológica. A negação da uniformidade de valores afirmados durantes séculos no mundo Antigo é posto em xeque, alterando o sistema social e as próprias convicções pessoais. A crítica ao mito e à leitura do mundo de forma sacralizada, baseada em uma estrutura bíblica-cristã-católica-romana foi fortemente disseminada na época moderna. Porém, isso ocorreu de forma especial na Europa Ocidental, ou, podemos dizer, no Ocidente, pois, nele, a racionalidade (Razão) e seu desenvolvimento se deu baseando-se na crítica as crenças míticas. Essa razão é "autônoma, teórica, prática e técnica, dessacralizadora da natureza, da sociedade e do poder e emancipadora do homem, agora sujeito de direitos inalienáveis, independentemente da sua religião, raça, sexo, idade ou condição" (PEREIRA, 1992, p. 206). Essa nova cosmovisão é uma crítica direta a qualquer forma de dependência servil, pensa de forma livre e independente o mundo, o Homem e Deus.

(...) é pertinente perguntar se saída da menoridade culpável da razão não será uma resposta racional requerida ao homem, como primeiro momento, pelo 'êxodo', em sentido bíblico. Este problema é fulcral na 
discussão das formas contemporâneas de fundamentalismo, pois, se é justa a crítica racional a toda a manipulação, repressão e eliminação do homem em nome do Sagrado, não é menos pertinente a crítica a toda a usurpação do Sagrado pelo poder hegemônico de uma razão autônoma capaz de absolutizar o seu próprio falibilismo" (PEREIRA, 1992, p. 207)

A modernidade propõe, assim, a libertação e a própria emancipação do homem, mas, como reverso, a solidão, o abandono. A ambiguidade da modernidade e a proposta do lluminismo, vencidas a utopia positivista de um futuro melhor com a secularização, revela "o rosto ambíguo e contraditório do iluminismo, privado agora de toda conciliação possível e sem forma própria definitiva revela-se em ritmo crescente uma séria ameaça para a vida humana e seus fundamentos" (PEREIRA, 1992, p. 208). O lluminismo, porém, com sua negativa de uma religião "dona da verdade" possibilita a liberdade e a autonomia do homem, somado a ele a secularização, que, com força afasta a metafísica, sendo esta uma contradição da razão por ser porta da revelação da religião. Os "dogmas sociais"se revelam, neste sentido, como as propostas iluministas formadoras de uma cosmovisão secularista, libertária, absoluta e autêntica, geradora de um espaço novo, configurado dentro de um espaço "profano", mas, profanado pela razão, ele não aceita a ambiguidade do espaço e exclui o "sagrado". Um espaço único, novo e sem nomenclatura. Um espaço de "dogma social". A verdade absoluta da modernidade é a razão e sua própria crítica.

O período atual (moderno/pós-moderno) se vê em seus pressupostos de ciência experimental e valorização do discurso jurídico/moral/ético, por vezes religioso, com a autonomia das produções artísticas e culturais e com a estrutura do capitalismo no empreendimento de um estado forte e burocrático, desfazendo e "reinventando" tradições, valorizando o indivíduo e suas pretensões pessoais vinculadas a um sistema social de coletividade que luta por um sentido de vida. Uma forma de enxergar essa realidade é produto, por assim dizer, de uma sociedade que se faz e refaz na pluralidade de identidades e na busca do próprio sentido que cada um tem para si. "Para além de uma razão aberta, 
dos direitos humanos, da democracia e do pluralismo não há na política moderna qualquer Absoluto que fosse seu ponto de Arquimedes"; "pois, os sistemas de uma razão aberta são envolvidos por um círculo fechado, que, numa audácia perigosa, põe fim à relação transsistémica e à possibilidade de outra época para além da Modernidade" (PEREIRA, 1992, p. 210).

Diante da modernidade e do iluminismo, surge o Fundamentalismo como uma possibilidade de resposta. Essa resposta se desdobra em movimentos religiosos, mas, não apenas nesta categoria, como também na política e na própria cultura. A busca por uma fé literal e repúdio a toda análise e crítica bíblica; a reintrodução no mundo ocidental do fundamento destruído pelo iluminismo, um discurso aberto e uma crítica à argumentação como se fosse um novo conhecimento; a busca por promessas míticas que forma coesão de pensamento e formação de seitas que trazem a desvalorização da autonomia - grupos espiritualistas; o exemplo do Estado de Israel em que o confronto de dois fundamentalistas provoca o ódio, a violência e a imposição a milhões de opositores de uma fé literal de tempos pretéritos como forma de lei obrigatória para a vida privada e pública (PEREIDA, 1992, p. 209). Existem, porém, outros vários exemplos de como o fundamentalismo tem adentrado na sociedade Ocidental Pósmoderna como consequência ao iluminismo e a razão.

Durante a Idade Média, percebe-se que o espírito conservador delimita a ação nas diversas esferas sociais. Porém, os novos paradigmas formadores de uma recém-criada cristandade, desafia o Homem aos novos desafios e as novas possibilidades que surgem com o advento do Novo Mundo. A velha religião repressora e de base essencialmente mitológica se torna inviabilizada. O espírito da ciência, pragmático, ganha espaço na sociedade, gerando uma abertura a novas ideias sobre a Religião e sobre os conceitos de Deus, Estado, Sociedade e Civilização. A modernização, neste contexto, se desenvolve mediante muita luta e um lento e dolorido processo de desenvolvimento na sociedade. Percebe-se que o mundo não é regulado por forças essenciais e imutáveis. Na modernidade, o Homem consegue controlar, em certa medida, seu ambiente mediante da razão; a racionalização. Assim, as forças mitológicas se enfraquecem diante da capacidade da razão e da explicação lógica. Assim, os valores como democracia e tolerância são mais percebidos e alimentados, diante de uma 
sociedade que acabara de sair de um período de dominação religiosa/política/ideológica.

Com a renovação trazida pelos ares iluministas, é possível perceber consequências da modernização. Diante da incerteza que a ausência religiosa trouxe ao europeu moderno, diversas pessoas perdem sua estrutura e sua identidade. Esse medo chega a ser traduzido em episódios de violência.

Constatamos algo parecido em Lutero. $\mathrm{Na}$ juventude ele tinha crises terríveis de depressão. Nenhum dos ritos e práticas medievais da fé conseguia tocar a 'tristitia' ('tristeza') que the infundia o pavor da morte, da completa extinção. Quando esse horror o dominava, era-lhe insuportável a leitura do Salmo 90, que descreve o esvaecimento da vida humana e a condenação dos homens pela fúria de Deus. Para ele a morte corresponde a uma expressão da ira divina. Segundo sua teologia de justificação pela fé, os seres humanos são incapazes de contribuir para a própria salvação e dependem inteiramente da benevolência divina. Só podem ser salvos entendendo sua impotência. Para fugir da depressão Lutero mergulhava numa atividade febril, decidido a fazer todo bem possível, mas também consumido pelo ódio. Sua raiva contra o papa, os turcos, os judeus, as mulheres e os camponeses rebeldes - para não falar de cada um de seus opositores teológicos - seria típica de outros reformadores da atualidade, que padeceram a dor do mundo novo e desenvolveram uma religião na qual o ódio ao semelhante muitas vezes se contrapõe ao amor de Deus. (ARMSTRONG, 2009, p. 98-99)

Neste sentido, Martinho Lutero se tornou um protótipo de cristão moderno. A fé na subjetividade individual, o expulso da razão da esfera religiosa e o processo de secularização podem ser classificados como visões rudimentares de Lutero (MITCHELL, 1993, p.23). Aqui, ocorre um afastamento do divino da esfera social, pois, a esfera sagrada faz oposição ao "mundo", ou a esfera 
"mundana". Igreja e Estado, assim, deveriam atuar de maneira diferente e separada. "Graças a sua apaixonada visão religiosa, Lutero foi um dos primeiros europeus a advogar a separação entre Igreja e Estado" (ARMSTRONG, 2009, p. 101).

O fundamentalismo, em seu desenvolvimento perante a modernidade, é visto na ação da negativa da ciência na resolução das questões da vida e dos mistérios do Homem. Galileu, ${ }^{80}$ por exemplo, estava convencido da graça de Deus em sua pesquisa ${ }^{27}$.Apesar de, em um primeiro momento, não haver choque entre ologos e o mythos, a ciência moderna inicia um processo de negação da religião nas questões profundas. Em síntese, quem era completamente adepto da razão e desejava praticar a religião, deveria reinterpretar a fé.

Diante desse impasse entre Razão e Fé - Mythose Logos -, observamos que a razão estava tornando a vida de diversos seres humanos melhor, porém, questões fundamentais da vida humana pareciam apenas ser explicadas, ainda, pelo Mito. Apesar disso, inicia-se uma era aonde a Razão tem seu domínio, entretanto, a relação entre ela e a religião ainda daria uma longa história.

A relação entre ciência e fé traria aspectos positivos e negativos para a modernidade. Sem dúvida que um dos aspectos mais negativos foi o fundamentalismo promovido pela má interpretação das duas. Apesar disso, alguns autores enxergavam a possibilidade de manter um equilíbrio, algumas instituições, não.

Locke tinha plena convicção de que o mundo natural oferece fartas provas da existência de um criador e que, se a razão pudesse agir livremente, cada qual descobriria a verdade por si mesmo. Ideias falsas e supersticiosas só começaram a aparecer no mundo porque o clero utilizou métodos cruéis e tirânicos, como a inquisição, para impor sua ortodoxia. Assim, pelo bem da religião verdadeira, o Estado devia tolerar todas as crenças e preocupar-se unicamente com a administração prática e o governo da

\footnotetext{
${ }^{80}$ Conforme Armstrong, 2003, página 103: "Os próprios cientistas consideravam suas investigações essencialmente religiosas. Kepler se sentia possuído de 'furor divino' ao revelar segredos que nenhum ser humano tivera o privilégio de conhecer, e Galileu estava convencido de que a graça divina inspirara sua pesquisa".
} 
comunidade. A Igreja e o Estado deviam separarse e não interferir nos assuntos um do outro. Locke viveu na Era da Razão e acreditava que pela primeira vez na história homens e mulheres seriam livres e, portanto, capazes de perceber a verdade. (ARMSTRONG, 2009, p. 109)

É justamente essa visão que estabelece os pilares do iluminismo, da tolerância e do Estado Moderno Secular. Mediante o Deísmo, filósofos, especialmente alemães e franceses, criticaram a religião mítica revelada. A revelação, portanto, era desnecessária, uma vez que o método para se chegar à verdade era a razão. Assim surge a aplicação dos pressupostos científicos a revelação cristã, especialmente.

Não se pode, entretanto, esquecer que, paralelo a este movimento crescente, surge na Europa e nos EUA, incentivadores de uma fé especialmente voltada para o interior. Jonathan Edwards e George Whitefield, alunos de Oxford e Yale, repetem que o cristão tem o livre direito de interpretar a bíblia livremente, isto é, sem uso de uma teologia acadêmica mais rebuscada. "Estavam reformulando o cristianismo num estilo popular muito distante do refinado etos da Era da Razão" (ARMSTRONG, 2009, p. 109). Esse movimento ganha uma considerável expressão, que desejava mudar a sociedade. Mobilizavam grande quantidade de pessoas. Esse movimento ficou conhecido como Primeiro Grande Despertar e, depois, Segundo Grande Despertar ${ }^{28}$. Eles, os profetas, proporcionavam a pessoas que se sentiam marginalizadas, possibilidade de pertencimento social. Voltavam-se aos grandes movimentos do passado, ao primitivo, e reconstruíam o sentido de uma fé nas origens. Seu apoio eram as Escrituras, que, de maneira geral, eram interpretadas literalmente, com uma forte ênfase no controle da vida dos fiéis. Sendo assim, um desejo de autonomia, direitos e igualdade, levaram um grande número de pessoas a se submeterem aos líderes carismáticos religiosos.

A publicação de uma lista de cinco dogmas essenciais pelos presbiterianos de Princenton, em 1910, deram um novo ar aos fundamentalistas. Esses pilares eram: a infalibilidade das Escrituras; o nascimento virginal de Jesus; a remissão de nossos pecados pela Crucifixão; a ressurreição da carne e a realidade dos milagres. Além desta publicação outra fortaleceu, ainda mais, a 
formação de uma visão fundamentalista da religião, especialmente cristã, que foi a intenção de educar fiéis nos princípios fundamentais da fé, proposta de Lyman e Milton Stewart, entre 1910 e 1915 . Foram doze panfletos, intitulados The fundamentals. Nestes panfletos, trabalhavam temas como a Trindade e enfatizavam a necessidade de pregação e expansão do evangelho. Porém, o movimento fundamentalista, como sucessão do conservador, especialmente nos EUA, ganhou notoriedade durante o contexto da Grande Guerra. A comparação entre o Apocalipse e a Primeira Guerra foi inevitável. Reuniram-se em grandes conferências, debatendo Profecias e Bíblias, se sentindo na linha de frente em uma batalha contra o mal. O Cristo do Apocalipse convidara todos para a luta (ARMSTRONG, 2009, p. 238239).

Assim como os movimentos fundamentalistas atuais, esses líderes se posicionam de uma maneira contrária à racionalização. Entretanto, se entrelaçam nos debates públicos e desenvolvem uma interpretação religiosa - de fé - para os dilemas da sociedade pós-modernas. Assim, conseguem inserir-se em na sociedade com interpretações fundamentalistas, porém, com uma nova formatação.

A partir dos anos de 1900, as interpretações acerca dos benefícios da Razão e do Progresso (Positivismo), geram uma resposta mais radical da religião, e, consequentemente, do fundamentalismo. As guerras mundiais destroem as esperanças de uma sociedade que falava e vivia a "modernização civilizadora". Os movimentos artísticos, intelectuais e culturais desejam recomeçar a descoberta em um mundo desordenado e cruel.

Novas formas de espiritualidade surgem. Novas interpretações da religião, também. O desejo de retorno ao fundamento é uma visão expandida no seio dos movimentos religiosos, especialmente, do cristianismo.

No início do século XX procuravam-se novas formas de religiosidade. Assim como a primeira Era Axial (c. 700-200 a. C.) descobriu que o velho paganismo já não funcionava nas novas condições da época e concebeu as grandes religiões confessionais, a segunda Era Axial enfrentava um desafio semelhante. Como todo empreendimento realmente criativo, a busca da 
fé moderna (e pós-moderna) é muito difícil. Até agora não surgiu nenhuma solução definitiva ou mesmo satisfatória. A religiosidade que chamamos 'fundamentalismo' é apenas uma de várias tentativas. (ARMSTRONG, 2009, p. 234-235)

\section{A “COSMOVISÃO” DE LUTERO E A RELAÇÃO ENTRE FÉ CRISTÃ, EDUCAÇÃO E MODERNIDADE}

A reforma protestante, como processo que norteou o desenvolvimento de uma espécie de novo cristianismo moderno, proporcionou uma nova abordagem na forma na qual os indivíduos vivem a fé e se relacionam com o mundo. Uma das principais concepções estruturante da reforma baseia-se no estudo do entendimento da Justificação pela Fé, corpo central do pensamento de Lutero. Como expresso no próprio texto bíblico: "O justo viverá pela fé" (Romanos 1:17). Lutero, em sua produção, desejava criar mais do que um conforto religioso aos que o ouvia, seu entusiasmo no processo de reforma era mais abrangente que isto. Não estava comprometido apenas com o sentimento antiromano que era alimentado pela religiosidade do "sacrifíciobenefício", mas, destacava a importância do relacionamento pessoal com Deus, o aprofundamento deste relacionamento espiritual e na vivência de uma fé engajada. É fundamental compreender a que é e como se desenvolve a fé em Lutero, pois, é essa fé que produzirá as atitudes para uma vida engajada e uma atuação possível no mundo moderno.

Estejamos esclarecidos que a ideia da fé em Lutero não tem nada em comum com qualquer tentativa de criar uma coragem ou força, um pensamento positivo em nós. Ela não 'pode ser relacionada a uma condição psicológica [ou mesmo sociológica] de confiança que pode existir sem um objetivo de confiança e separada de um relacionamento pessoal com Deus]. A fé é uma relação entre Deus e o homem, 'toda declaração de fé é uma afirmação concernente a Deus e ao homem ao mesmo tempo'. 'Esses dois termos, 
Deus e fé, são unidos e devem ser associados', afirmou Lutero ${ }^{81 " .}$

Deste modo, a concepção de Lutero, que hora apresento como um pilar importante da reforma, pode ser compreendida como expressão da reforma que proporcionou um certo comportamento, uma possível cosmovisão, um jeito de viver a fé cristã no período posterior a reforma e no contexto do mundo pósmoderno, ou seja, no modernismo presente. Essa possibilidade de viver uma fé que ultrapassa a categoria de subjetividade, pois, está além dela, é a possibilidade de viver uma fé relacional, pessoal e engajada, pois, apesar de estar além do "presente tempo", não está "aquém" dele, mas, promove uma vida engajada e transformacional82. Cabe destacar que essa vida gera um relacionamento com Deus e O promove no cristão. Não O cria, mas, permite uma vivência aproximada com o Espírito de Deus, que $\mathrm{O}$ move no indivíduo e o lança para uma vida nova. (LUTERO, 2000).

A reforma, ou, aqui exposta no pensamento de Lutero, trouxe um despertar de categorias (expressões; dogmas; crenças) da fé cristã, ou do Evangelho de Jesus, que podem gerar um impacto positivo nas diversas dimensões do desenvolvimento da humanidade. Surge, aí, uma cosmovisão que pode promover mudanças na política, na educação, na cultura, na arte, nos negócios e em outas dimensões do mundo moderno. Mesmo o humanismo confessional ${ }^{83}$ sendo dominante e havendo tensa relação entre a fé o iluminismo - decadente.

Este desafio não impede a fé cristã de sobreviver ou mesmo de ser relevante diante do Modernismo.

\footnotetext{
${ }^{81}$ SILVA, Juvan Vieira da. Sola Fide - A compreensão de Martinho Lutero sobre a fé na epístola aos Romanos. Universidade Presbiteriana Mackenzie. Disponivel em <file:///C:/Users/Paula\%20Ang ela/Downloads/4060-10678-1-PB.pdf> Acessado em 22 ago. 2018.

82 Para aprofundar a "linguagem" transformacional ver <http://ultimato.com.br/sites/guilherm edecarvalho/2015/07/16/1026/> Acessado em 22 ago. 2018.

${ }^{83}$ Termo utilizado por Michel W. Giheen e Graig G. Bartholomew no livro Introdução à Cosmovisão Cristã. Editoria Vida Nova. Pg. 115.
} 
O Evangelho é uma visão abrangente de vida, mas é também adaptável ou traduzível em todas as culturas. Ela não se apresenta apenas como uma alternativa independente à cosmovisão cultural predominante. A própria natureza do evangelho é encarnacional: isso permite - aliás, exige - que ele lide com várias formas culturais, mas sem abrir mão de suas exigências abrangente. O propósito não era que o evangelho continuasse sendo só judaico; era que encontrasse acolhida em cada cultura para onde ele deslocasse. O evangelho reconhece as percepções intuitivas genuínas de qualquer cultura, incluindo aquelas da cultura clássica pagã em que foi inicialmente inserido. (GOHEEN; BARTHOLOMEW; 2008; pp. 122)

Nos aspectos educacionais é fundamental a contribuição de Lutero para o mundo no cenário moderno. Lutero foi um defensor de uma escola pública de qualidade e com uma ampla formação no Grego, Latin e disciplinas como Lógica, Música, Matemática, Gramática e Ciências.

Lutero considerava a educação universal de fundamental importância para a Reforma. Por isso, insistia, em suas pregações, que o ensina deveria chegar a todo povo, nobre e plebeu, rico e pobre. E contrariando o que se pensava e fazia na época, ele deveria beneficiar tanto meninos como meninas. Caberia a Estado, finalmente, decretar a frequência obrigatória da escola. (PILETTI; CLAUDINO, 2016; p. 63)

Este aspecto é interessante, pois, apresenta o ensino universal, para todos, independentemente de sua realidade especial. Sendo assim, a educação deve contemplar aqueles menos favorecidos. Entretanto, mais do que isso, Lutero está interessado na formação integral dos seres humanos, pois, sua proposta é a inserção de conhecimento que promovam dimensões científicas, culturais, artísticas etc. 
As concepções de Lutero sobre Educação, principalmente sobre uma educação cristã, acabam perpassando todos os seus tratados e escritos na medida em que neles expõe e ataca os problemas da igreja e também da sociedade, aconselhando-as como deveriam ser. Contudo, é em dois textos específicos que ele registra sua posição sobre a educação escolar: Aos conselhos de todas as cidades da Alemanha para que criem e mantenham escolas cristãs, carta escrita em 1524, e uma prédica para que se mandem os filhos à escola, sermão proferido em 1530 (BARSOSA, 2007, p. 166)

Lutero ressalta a importância da educação inserida no contexto da necessidade de uma Reforma que não se encerrava nos dogmas da igreja romana. Tendo em vista, para ele, a importante participação do Estado no fornecimento de uma educação de qualidade, apresenta a necessidade de uma reforma que reestruturasse toda a sociedade de uma maneira integral.

Entretanto, as ideias educacionais de Lutero foram inseridas na Alemanha não por sua própria atuação ou por seu esforço pessoal, mas, coube a Felipe Melanchton. Na universidade de Wittenberg, onde trabalhou, Melanchton promoveu a visão de Lutero em uma formação cristã, mas que ultrapassava as concepções religiosas e promoviam uma visão integral na construção do conhecimento humano.

Na educação com base nas ideias da Reforma promovidas por Lutero, temos a criação de escolas que ensinassem a Bíblia, as línguas clássicas para o entendimento das Escrituras Sagradas; também "chega a recomendar o ensino de música, com toda matemática necessária, a jurisprudência e a medicina, entendidas essas duas últimas como sendo recomendação para a universidade" (BARBOSA; 2007; pp. 169). Lutero propõe, ainda, que na escola não existam punições severas,

Segundo ele, na escola, o ensino deveria acontecer com prazer e por meio de brincadeiras. A posição apresentada é em favor de uma educação lúdica, resgatando o exemplo da 
educação grega cujo alto padrão, segundo ele, se infere das qualidades do povo que nela se forjou. Se os jovens gostam de dançar, cantar e pular e estão sempre em busca de algo que lhes dê prazer, então que as disciplinas sejam estudadas com prazer e brincando. (BARBOSA, 2007; p. 171)

Desta forma, um dos pilares da educação da reforma com base em Lutero, é a escola como agente de formação bíblica e integral para o indivíduo, com participação do estado na oferta e manutenção deste ensino, promovendo uma transformação integral da cidade em seus diversos aspectos.

Lutero,

Propõe a responsabilidade aos conselhos municipais das diversas cidades da Alemanha, ou seja, o sustento econômico para a criação e manutenção das escolas seria de responsabilidade das instituições políticas locais, afinal: "A eles, como curadores, foram confiados os bens, a honra, corpo e vida de toda a cidade" (Lutero, 1995, p. 309) (BARBOSA, 2017, p. 173)

\section{CONSIDERAÇÕES FINAIS}

Diante do exposto, chegamos ao entendimento de que a realidade da Modernidade propões uma individualidade, uma separação da vida religiosa da secular e uma educação que não interfira na formação espiritual do indivíduo. Entretanto, na concepção da Reforma, os pressupostos educacionais reestruturam uma nova interpretação pessoal diante da Modernidade. Uma formação educacional protestante, especialmente, na concepção de Lutero, forma o cidadão em uma perspectiva integral, fazendo-o inserir-se nas diversas dimensões da sociedade, pois, apesar da experiência ser pessoal a sua prática é mais abrangente que a dimensão individual. Na formação educacional, consequentemente, é valorizada a formação bíblica para que se conheça e se viva a fé cristã de uma maneira relevante; integral. Nesta concepção há, inclusive, a aproximação entre o Estado e a Igreja, pois, segundo Lutero, o Estado deve garantir uma 
educação de qualidade, sendo essa educação de qualidade integral e com o ensino bíblico, fundamental para a compreensão social, política e cultura de sua época. Assim, através do trabalho na educação de Lutero, viv-se uma Cosmovisão Cristã, inevitavelmente.

Martinho Lutero afirmou certa vez que o evangelho é como um leão enjaulado que não precisa ser defendido - apenas libertado. Certamente o evangelho é o poder de Deus para a salvação (Rm 1.16; 1Co 1.18). Quando está em ação nas palavras, obras e vida do povo de Deus, ele alcançara seus propósitos. Mas o evangelho está "enjaulado" quando se acomoda à narrativa do humanismo. Só quando o evangelho estiver livre de seu cativeiro à narrativa cultural dominante é que a igreja estará equipada para sua missão abrangente na cultura dominante é que a igreja estará equipada para sua missão abrangente na cultura ocidental. (GOHEEN; BARTHOLOMEW; 2008; pp. 35)

\section{REFERÊNCIAS}

ARMSTRONG, Karen. Em nome de Deus: o fundamentalismo no judaísmo, no cristianismo e no islamismo / Karen Armstrong; tradução de HildegardFeist, - São Paulo: Companhia das Letras, 2009.

BARBOSA, Luciane M. R. As concepções educacionais de Martinho Lutero. Educação e Pesquisa, São Paulo, V. 33, n. 1, p. 163-183, jan./abr. 2007.

BAUMAN, Zygmunt. Medo Liquido. Rio de Janeiro: Jorge Zahar, 2008.

CHAUI, Marilena. Fundamentalismo religioso: a questão do poder teológico-político. In: NOVAES, Adauto (org.). Civilização e barbárie. São Paulo: Companhia das Letras, 2004. p. 149-169.

GIDDENS, Anthony. Mundo em descontrole: o que a globalização está fazendo de nós. Trad. Maria Luiza X. de A. Borges. Rio de Janeiro: Record: 2000. 
GOHEEN; Michael W; BARTHOLOMEW; Graig G. Introdução à cosmovisão cristã: vivendo na intersecção bíblica e a contemporânea. Tradução de Marcio Loureiro. São Paulo: Vida Nova, 2016.

GRUMAN, Marcelo. O lugar da cidadania: Estado moderno, pluralismo religioso e representação política. Revista de Estudos da Religião. n. 1, 2005, p. 95-117.

LUTERO, Martinho. Tratado sobre a liberdade cristã. In: Obras selecionadas. vol. 2. Trad. Ilson Kayser. São Leopoldo/RS: Sinodal, RS: Concórdia, 2000, p. 436.

MELCHIOR, Marcelo do Nascimento. A religião pós-moderna em Zygmunt Bauman. Sociabilidades religiosas: mitos, ritos e identidades. XI Simpósio Nacional da Associação Brasileira de História das Religiões. 2009. p 1-11.

MITCHELL, Joshua. Not By Reason Alone: Religion, History and Identity in Early Modern Political Thoutht. Chicago, 1993.

PEREIRA, Miguel Baptista. Modernidade, Fundamentalismo e Pós-modernidade. Revista Filosófica de Coimbra - 2 (1992). Disponível em <www.uc.pt/pluc/dfci/publicacoes/modernidade> Acesso em 12 fev. 2018.

PIERUCCl, Antônio Flávio. Ciladas da diferença. São Paulo: Curso de pós-graduação em Sociologia da Universidade de São Paulo; Editora 34, 1999.

PILETTI, Claudino. História da Educação: de Confúcio a Paulo Freire. $1^{\text {a }}$ ed., $3^{\text {a }}$ reimpressão. São Paulo: Contexto, 2016.

SILVA, Juvan Vieira da. Sola Fide - A compreensão de Martinho Lutero sobre a fé na epístola aos Romanos. Universidade Presbiteriana Mackenzie. Disponível em <file:///C:/Users/Paula\%20Angela/Downloads/4060-10678-1PB.pdf> Acesso em 12 fev. 2018. 